\title{
Effects of Aging Temperature, Time During Transition from Brittle to Ductile on Fracture Behavior of Zinc Coated AA7075
}

\author{
Ramesh Manjunath*, Deepak Kumar \\ Department of Mechanical Engineering, University of Petroleum and Energy Studies, Dehradun 248007, India
}

Corresponding Author Email: rameshm@ddn.upes.ac.in

https://doi.org/10.18280/acsm.440308

Received: 25 February 2020

Accepted: 10 April 2020

\section{Keywords:}

age hardening, coating, facture toughness, scanning electron, microscope, brittle to ductile transition temperature

\begin{abstract}
During coating, the post-baking phase of the coated material has shown maximum impact on the fracture toughness and the parameters during the coating process have shown their own influence during the heat-treating the materials. To know the effect of this, the experiments are done on the age hardened specimens. Age hardening of aluminum is carried out in the following ways; one by varying the temperature of aging and the other by varying the time of aging. The results found from both the experimental and the fractographic analysis have shown that, the variation in the fracture toughness of the materials is mainly due to the changes found in the grain structure of the materials. The results obtained during the experiments have shown that, the fracture behavior of the coated and heat-treated aluminum a material is changed significantly.
\end{abstract}

\section{INTRODUCTION}

The use of aluminum alloys in automobile engine components has been concern by a number of issues, in particular weight reduction. The need for materials which are capable of operating at elevated temperatures in oxidizing atmospheres has become increasingly critical in recent years. Applications in the nuclear, missile and space industries are presently demanding materials which will function at temperatures in the order of $1100^{\circ} \mathrm{C}$. The heat treatable $\mathrm{Al}-$ $\mathrm{Mg}-\mathrm{Si}$ alloys of the 7xxx series are selected often for these applications, since they exhibit a superior combination of formability, corrosion resistance and weldability [1]. The strengthening of $\mathrm{Al}-\mathrm{Mg}-\mathrm{Si}$ alloys is based on a precipitation hardening process. Age hardening is a process, which enhances the strength and hardness of aluminum alloys by forming very tiny particles, which are dispersed uniformly in a second phase within the phase of original matrix [1]. The heat treatment is done by either natural ageing or artificial ageing, in which the natural ageing takes more time to modify the mechanical properties, which made it to replace by artificial ageing which is dependent on both the temperature and time of ageing [2]. The desired properties of aluminum are attained by heat treatment during which the small hard precipitates are added in the form of alloying elements [3]. Aluminum 7075 is most widely used for structural applications because of its significant properties like high strength, low density, ductility and toughness [4-7]. Aluminum 7075 is extensively used in aircraft structural components and structures which are under highly stress [812] and have noticed in their study that the best ageing can be achieved with an ageing time duration of $2-6$ hours under the temperature range of $175^{\circ} \mathrm{C}$ to $195^{\circ} \mathrm{C}$. Alaneme and Aluko [13] have demonstrated that the ageing process has vital role in improving fracture toughness than the strength of the material. Smallman and Ngan [14] have observed during their studies, that an artificial age hardening of aluminum alloy
6061 - T6 shown decreased solubility limit when the ageing temperature is decreased. Lumley et al. [15] have observed an increase in stress, fracture toughness, for a wide range of aluminum alloys in comparison with that of conventional T6 tempered alloys during ageing. Cheng et al. [16] have conducted tensile test on AL 6111 alloy after different artificial ageing treatments in order to study the effect of precipitation on its yield stress and work-hardening nature. Gao et al. [17] have conducted experiments to know the influence of ageing on the tensile strength and microstructure of aluminum alloy 6063 , which are treated under different preageing conditions at $165^{\circ} \mathrm{C}, 185^{\circ} \mathrm{C}$ and $205^{\circ} \mathrm{C}$ for a range of 25 to 64 hours). Kilic et al. [18] have studied the effects of aging temperature and time on AA 7075 and noticed reduction in the yield stress value under increased aging temperature. They also mentioned that AA7075 with T6 temper under dissolved state is evident to brittle fracture with higher hardness value. Karaaslan et al. [19] have performed heat treatment on AA 7075 specimens by quenching them in water for 6 seconds and aging at $130^{\circ} \mathrm{C}$ for $12 \mathrm{hrs}$ and noticed decrement in hardness and ultimate strength and increment in impact toughness. Kaçara and Guleryuzb [20] have studied the effect of quenching during solution heat treatment, ageing time, temperature of ageing and pre-strain on the mechanical properties of $7075 \mathrm{Al}$-alloy samples at $480^{\circ} \mathrm{C}$ for $2 \mathrm{~h}$ and then pre-strained for $8 \%$ in tension. Sato et al. [21] have noticed an increase in the strength, yield strength, tensile strength and hardness of 7075 aluminum alloys when heat-treated at different aging durations at $140^{\circ} \mathrm{C}$. Mroczka et al. [22] have discussed the effect of various conditions of heat treatment on the aluminum alloy under a particular temperature of $500^{\circ} \mathrm{C}$. Gowrishankar et al. [23] have noticed reduced strength and increased toughness under increased ageing temperature during their experiment on artificial ageing of solutionized $\mathrm{Al}$ 6061 alloy at $100^{\circ} \mathrm{C}, 150^{\circ} \mathrm{C}$ and $200^{\circ} \mathrm{C}$ under the influence of precipitation. Howell, Ryan A [24] have conducted experiment on the solutionised heat treated specimen $\left(1050^{\circ} \mathrm{C}\right.$ 
for 5 minutes and water quenched) and observed the lowest yield strength at highest elongation, greater Charpy impact energy, and higher fracture toughness. The fully aged specimen (solution treated and aged 15 hours at $550^{\circ} \mathrm{C}$ ) had the highest strength and hardness but lowest ductility and toughness values. He also noticed balanced mechanical properties by controlled cooling from solution treating temperatures. Micro void coalescence was observed for fracture of the solution treated specimen, and the aged microstructure produced brittle grain boundary or cleavage fracture. Formation and ordering of the $\mathrm{\kappa}$-carbide were primarily responsible for the simultaneous increase in strength and reduction in impact toughness and cleavage fracture was not observed in the specimen that had been controlled cooled.

Barsom [25] have observed that for the structures operating at higher temperatures with T 4 and $\mathrm{T} 6$ tempered alloys and revealed that both mechanical and physical properties of T6 tempered alloy has higher strength, and low ductility compared to T4 tempered alloy, Kilic [26] have studied the effects of aging temperature, time, and pre-strain on mechanical properties for AA7075 and observed the increased strength under the distribution of $\mathrm{MgZn}_{2}$ dispersions increases the strength. They also have seen that AA7075 with T6 temper is exposed to brittle fracture, which exhibit ductile failure. Ashjari and Feizi [27] have expressed that aging temperature and quench-induced precipitation play significant role in improving mechanical strength, which is observed under microscopic studies. Liu et al. [28] have studied the effect of solution and aging system on microstructure and mechanical properties of 7000 series aluminum alloy produced by powder metallurgy and noticed decrement in the undissolved phase in the aluminum alloy under increased temperature and time. Priya et al. [29] have studied effect of precipitation during post-homogenization cooling and evaluated its effect of cooling rates and compositions on the precipitation response. He et al. [30] have investigated the mechanical properties and microstructure of the extruded 6082 alloy at $175^{\circ} \mathrm{C}$ and 8 hours which shown enhanced mechanical properties during aging precipitation process and keeps the alloy in a stable microstructure $s$ to improve the final properties of the alloy. Before age hardening, it is required to undergo number of intermediate processing steps. Initially, a homogenization heat treatment is used to remove micro segregation, dissolve low melting interdendritic particles, and to precipitate the dispersoids. The metal is then solution treated to make it to supersaturated solid solution before aging when precipitation of strengthening particles occurs. Room temperature cooling is required after each high temperature processing. Thus, microstructure after quenching is the initial condition for the next processing step. The occurrence of a brittle-to-ductile transition in metals has been recognized for many years. This ductility transition results in an abrupt change from brittle behavior to ductile behavior over a very narrow temperature range.

\section{MATERIALS AND METHODS}

Charpy impact testing has been done on the age hardened zinc coated aluminium 7075 material. The specimen preparations and experimentations implemented are mentioned below.

\subsection{Substrate material}

Aluminium7075 material is taken as substrate because of their wide range of applications in aerospace and many other engineering applications and readily availability having composition of $6.1 \mathrm{wt} . \% \mathrm{Zn}, 1.2 \mathrm{wt} \% \mathrm{cu}, 0.23 \mathrm{wt} . \% \mathrm{Cr}$, rest $\mathrm{Al}$ and the main mechanical properties are: yield strength $=435$ Mpa, ultimate strength $=505 \mathrm{Mpa}$, young's modulus $=72 \mathrm{Gpa}$, hardness $=135 \mathrm{BHN}$

\subsection{Coating}

The experimentations have been carried out on Al 7075 material, which is coated with zinc. The typical coating bath used for coating contains 2 to $4 \mathrm{oz} / \mathrm{gal}$ of zinc chloride and 16 to $20 \mathrm{oz} / \mathrm{gal}$ of ammonium chloride. The coating bath is maintained around $40^{\circ} \mathrm{C}$ to $75^{\circ} \mathrm{C}$ with a deposition rate of 6 $\mu \mathrm{m}$ to $10 \mu \mathrm{m} / \mathrm{h}$. The coating thickness is proportional to the Immersion time into the bath, which typically ranging from 3 to 6 min during which the consistency in the coating depends on the withdrawal speed at which the specimen withdrawn from the immersion.

\subsection{Specimen preparation}

The specimen is a square bar of $10 \mathrm{~mm} \times 10 \mathrm{~mm} \times 55 \mathrm{~mm}$ having a $\mathrm{V}$ notch cut at the center of its face with an angle of $45^{\circ}$, root radius of $0.25 \mathrm{~mm}$ and with a depth of $2 \mathrm{~mm}$. A rolled bar stock is used to fabricate specimen as per ASTM E 23 type A standards. A constant thickness of zinc coating is applied uniformly on the surface of the specimens.

Specimens are heated in a furnace from $75^{\circ} \mathrm{C}$ to $300^{\circ} \mathrm{C}$ in multiples of $75^{\circ} \mathrm{C}$. Then they are quenched quickly in water.

\section{EXPERIMENTATION}

The experiment has performed on the pendulum type impact-testing machine during which the specimen absorbs some quantity of energy before it fractures. The ductile-tobrittle transition can be measured by impact testing: The impact energy required to fracture, allowed dropping suddenly over a relatively narrow temperature range of the ductile-tobrittle transition $[31,32]$. The Charpy impact test, also known as the Charpy V-notch test, is a high strain-rate test, which involves striking a notched specimen with a pendulum swung from a certain height. The specimen is supported at its two ends on an anvil and struck on the opposite face to the notch by the pendulum. The amount of energy absorbed to fracture the specimen is measured which gives an indication for toughness of the specimen. The pendulum swings through during the test, the height of the swing is measured to know the amount of energy absorbed in breaking the specimen. The impact test helps to measure the amount of energy absorbed by the specimen during fracture. The amount of energy absorbed by material is due to its nature. i.e., due to its brittleness nature, the fracture occurs readily by absorbing lesser amount of energy and due to its toughness, it requires more energy to rupture it [32]. Before placing the specimen in a position to be tested, the pendulum of machine is checked for its free swing with the indicator at the initial position to indicate zero energy on a machine reading and the quantity of energy absorbed by the specimen prior to its fracture, is noted directly from a graduated scale, present in the impact testing 
machine [24, 32].

\section{RESULTS AND DISCUSSION}

For high temperature applications, one important mechanical parameter of material is the ductile-brittle transition temperature (DBTT), above which dislocations within the material are able to overcome obstacles to produce more plastic deformation. DBTT is essentially dependent on the composition and microstructure but is also influenced by the coating deposition process, heat treatment history and operating environments the specimens were pre heated during its pre cleaning stage before it is being coated and then immersed in coating bath. Before the specimens were coated with powder, they were heated to their elevated temperature. Again, after coating they are baked by keeping in furnace. These temperature variations happened during the process of coating; the specimens are considered similar to that of the age hardening temperatures of the aluminum. To understand this effect of variations in temperature during coating, the experiments were performed on the age-hardened specimens. Age hardening of aluminum is carried out in the following ways; one by varying the temperature of aging and the other by varying the time of aging. Precipitation hardening also known as age hardening which involves hardening of a material over a prolonged time which is accomplished by two steps .one solution treatment and ageing. The results are plotted in the Figures $1 \& 2$ respectively.

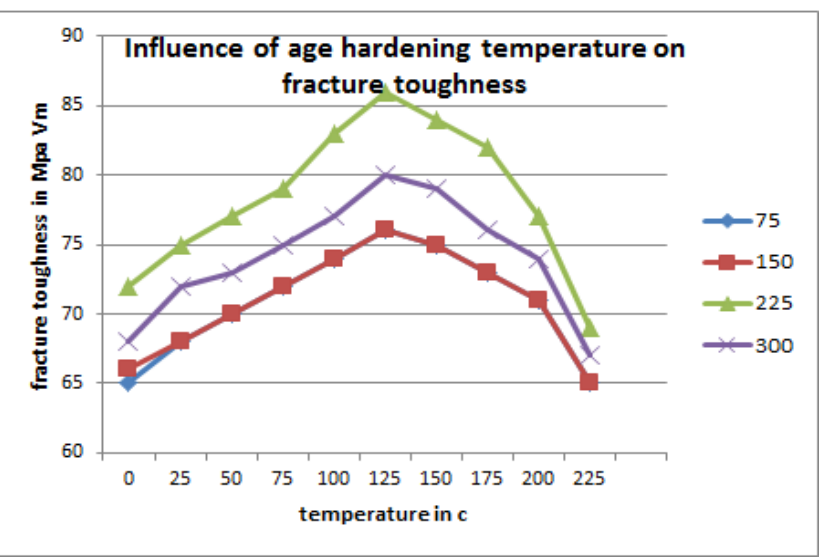

Figure 1. Influence of age hardening temperature on fracture toughness

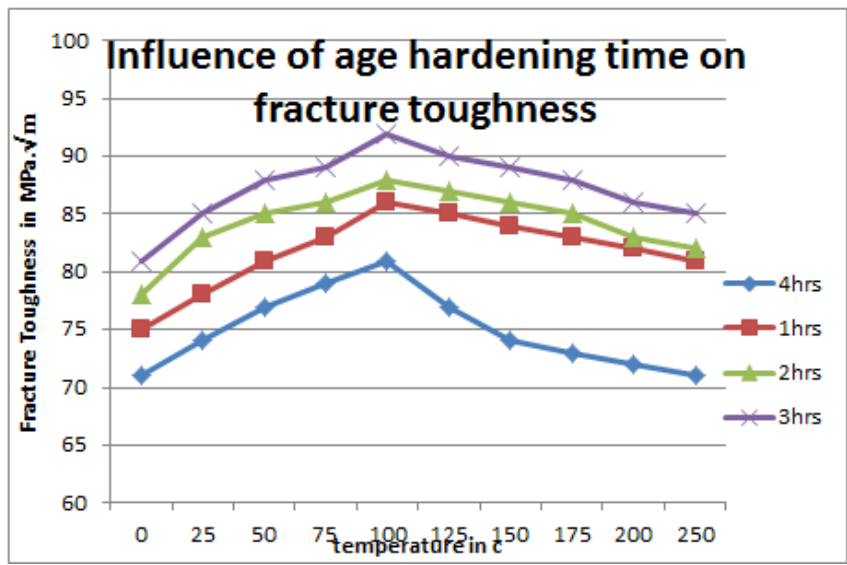

Figure 2. Influence of age hardening time on fracture toughness
The specimens were initially heated to $600^{\circ} \mathrm{C}$ in a furnace for duration of three hours before they were quenched in water. Again, the specimens are heated to different temperature ranging from $50^{\circ} \mathrm{C}$ to $300^{\circ} \mathrm{C}$ in steps of $50^{\circ} \mathrm{C}$. At these temperatures, the specimens were kept persistent in a furnace for duration of one hour. It is noticed that the fracture toughness was found to increase for the corresponding increase in ageing temperature. Maximum fracture toughness of $90 \mathrm{MPa} \sqrt{\mathrm{m}}$ is obtained for an ageing temperature of $225^{\circ} \mathrm{C}$. It is shown clearly from Figure 1, that, when ageing temperature increased beyond $225^{\circ} \mathrm{C}$, the fracture toughness was decreased correspondingly.

Further, the experiment was conducted for another set of specimens by varying the ageing time by keeping the ageing temperature as constant (at $225^{\circ} \mathrm{C}$ ). The specimens were age treated at different intervals of time ranging from one hour to four hours at incremental steps of one hour. The specimens aged at three hours of span were shown maximum fracture toughness of $95 \mathrm{MPa} \sqrt{\mathrm{m}}$ which is higher than that of both the untreated and the aged specimens at constant time. From this experimental analysis, it is found that, during ageing process, both the yield strength and hardness of the specimen have been increased. However, after a particular fixed ageing temperature of $225^{\circ}$ with a constant ageing duration of one hour and of three hours, the specimens have shown reduced yield strength and hardness because of the effects of over ageing. Hence, there is a drastic decrease in the fracture toughness of the over aged specimens. During the process of coating, the presence of chemicals made the material to attain over aged condition with a corresponding reduced temperature and ageing time. Same results were noticed from fractographic examination also. It is clearly observed from these examinations that the coating thickness, which depends on the bath concentration and the duration of time, affects significantly the fracture behavior. Further, it is noticed that the heat treatment (age hardened and water quenching) is mainly responsible for the variations in the fracture toughness of the coated materials. The results were plotted as shown in the Figure 3.

\section{Influence of Water Quenching on Fracture Toughness of Material}

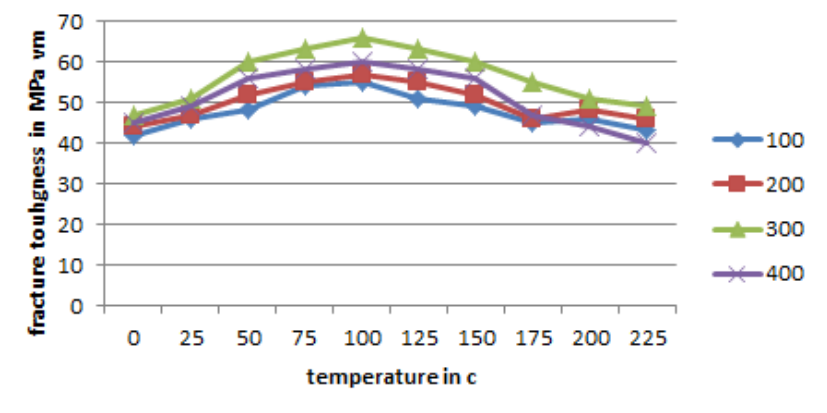

Figure 3. Influence of water quenching on fracture toughness

During coating process, the specimens are immersed in the coating bath for a specified duration of time. Before immersion, the specimens were precleaned with cleaning agents at some elevated temperatures. At the time of immersion, the specimens were at a temperature higher than that of room temperature, which induced a quenching effect on the specimens. To identify the effect of quenching on the 
materials, experimentations were carried on water-quenched specimens, which are quenched at different temperatures.

Water quenching has no significant effect on the BDTT of aluminum. The influence of service temperature on the fracture toughness of the coated material is same as that of the untreated materials. However, the fracture toughness is found to be increased for a value of $68 \mathrm{Mpa}$ up to the quenched temperature of $300^{\circ} \mathrm{C}$. It has been identified that the water quenching reduced the yield strength and hardness increased drastically. However, because of high cooling rate, maximum cracks were found in water-quenched specimens. It has been found in SEM fractography as shown in Figure 4 a \& b.

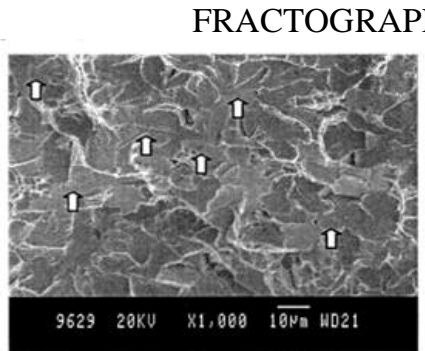

(a)

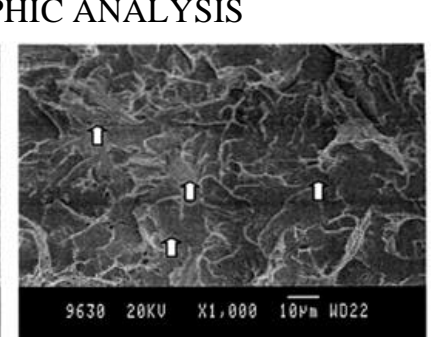

(b)
Figure 4. (a) Coated specimen; (b) uncoated specimen

The SEM scans clearly shown the dimples both in coated and uncoated specimens as shown in above figures, but there is difference in the fractured facets is observed. The main variance lies is in terms of the number of cleavage sites and their areas. As observed from the scan, the noticed area of the cleavage sites is more for coated materials, which is indicated by arrows. This feature indicates the plastic deformation during tensile is very limited. This increased area of the cleavage sites shows increased rate of crack growth and its propagation at which induced stress is observed. It is found that, the fracture nature has changed from dimpled to brittle fracture for a coated specimen. This made the crack to propagate at very high speed and held responsible for a catastrophic failure due to the accumulated stress as observed. From this, it is found that the effect of heat treatment on the specimen depends on the duration for which the specimen is kept in the coating bath and temperature at which it is underwent ageing.

In case of aluminum, the maximum fracture toughness is obtained under aged condition (with constant temperature of $225^{\circ} \mathrm{C}$ and with an ageing time of 1 hour). Maximum enhancement in mechanical properties is attained when the temperature of the solution heat treatment is within the range of specified temperature. If there is low temperature, the mechanical properties will be below requirements and if there is higher temperature, there is a possibility of cracking due to overheating.

\section{CONCLUSIONS AND FUTURE SCOPE}

\subsection{Conclusions}

Following points have been concluded from the present experimental studies:

i. The ageing process affects the fracture toughness of the coated materials in comparison with untreated materials. ii. The duration of time at which the specimens were kept in coating bath during coating process during ageing process affects the strength and toughness of the materials.

iii. Fracture toughness of the material found to be increased up to $225^{\circ} \mathrm{C}$ for the corresponding increase in ageing temperature with an incremental step of $25^{\circ} \mathrm{C}$ by keeping the duration time as constant for one hour).

iv. The hardness and yield strengths were increased up to 3 hours of ageing time for every one-hour rise in time, by keeping the temperature as constant at $225^{\circ} \mathrm{C}$. Beyond which the hardness and yield strengths were reduced due to over ageing.

v. Water quenching process has no significant effect on the BDTT of material.

vi. The influence of service temperature on the fracture toughness of the coated material is same as that of the untreated materials.

\subsection{Future scope}

i. The work can also be continued in the determination of fracture toughness of coated and heat-treated materials under cryogenic temperatures

ii. The investigation can also be made to analyze the fracture behavior at the interface of coating and substrate material.

\section{ACKNOWLEDGMENT}

Thanks to the co-author for the cooperation and for the work done. Thanks to Assistant Editor, ACSM, for the speed of the editorial process and for the support given to the corresponding author. The author(s) received no financial support for the research, authorship, and/or publication of this article.

\section{REFERENCES}

[1] Heinz, A., Haszler, A., Keidel, C., Moldenhauer, S., Benedictus, R., Miller, W.S. (2000). Recent development in aluminum alloys for aerospace applications. Materials Science and Engineering, 280(1): 102-107. https://doi.org/10.1016/S0921-5093(99)00674-7

[2] Williams, J.C., Starke Junior, E.A. (2003). Progress in structural materials for aerospace systems. Acta Materialia, $\quad 51(19)$ : 5775-99. https://doi.org/10.1016/j.actamat.2003.08.023

[3] Clark, R., Coughran, B., Traina, I., Hernandez, A., Scheck, T., Etuk, C., Peters, J., Lee, E.W., Ogren, J., EsSaid, O.S. (2005). On the correlation of mechanical and physical properties of 7075-T6 Al alloy. Engineering Failure Analysis, 12(4): 520-526. https://doi.org/10.1016/j.engfailanal.2004.09.005

[4] Li, J.F., Peng, Z.W., Li, C.X., Jia, Z.Q., Chen, W.J., Zheng, Z.Q. (2008). Mechanical properties, corrosion behaviors and microstructures of 7075 aluminum alloy with various aging treatments. Transactions of Nonferrous Metal Society of China, 18(4): 755-62. http://dx.doi.org/10.1016/S1003-6326(08)60130-2

[5] Lee, W.S., Sue, W.C., Lin, C.F., Wu, C.J. (2000). The strain rate and temperature dependence of the dynamic 
impact properties of 7075 aluminum alloy. Journal of Materials Process and Technology, 100(1-3): 116-122. http://dx.doi.org/10.1016/S0924-0136 (99)00465-3

[6] Lin, G.Y., Zhang, H.M., Zhang, X., Han, D., Zhang, Y., Peng, D. (2003). Influences of processing routine on mechanical properties and structures of 7075 aluminium alloy thick plate. Transactions of Nonferrous Metal Society of China, 13(4): 809-813.

[7] Wut, S., Lwin, K.T., Oo, K.K., Aye, H., Waing, W. (2008). The effect of ageing treatment of aluminum alloys for fuselage structure-light aircraft. World Academy of Science, Engineering and Technology, 46: 696-699.

[8] Zhao, T.W., Jiang, Y.Y. (2008). Fatigue of 7075-T651 aluminum alloy. International Journal of Fatigue, 30(5): 834-849. https://doi.org/10.1016/j.ijfatigue.2007.07.005

[9] Mohammad, T., Ismail, E. (2010). Mechanical and anisotropic behaviors of 7075 aluminum alloy. Materials and Design, 32(2): 1594-1599. http://dx.doi.org/10.1016/j.matdes.2010.09.001

[10] Balamugundan, B., Karthikeyan, L., Karthik, K., Keerthi, C. (2014). Enhancement of mechanical properties on aluminum alloys- A review. Journal of Mechanical and Civil Engineering (IOSR-JMCE), 05-07.

[11] Isadare, A.D., Aremo, B., Adeoye, M.O., Olawale, O.J., Shittu, M.D. (2012). Effect of heat treatment on some mechanical properties of 7075 Aluminium alloy. Materials Research, 16(1): 190-194. http://dx.doi.org/10.1590/S1516-4392012005000167

[12] Tan, C.F., Said, M.R. (2009). Effect of hardness test on precipitation hardening aluminum alloy 6061-T6. Chiang Mai J. Sci., 36(3): 276-286.

[13] Alaneme, K.K., Aluko, A.O. (2012). Fracture toughness (KIC) and tensile properties of as cast and age hardened aluminum (6063) - silicon carbide particulate composites. Scientia Iranica, 19(4): 992-996. https://doi.org/10.1016/j.scient.2012.06.001

[14] Smallman, R.E., Ngan, A.H.W. (1985). Modern physical metallurgy. 4th edition. London: Butterworths \& Co. ASIN: B00FAGJD7A

[15] Lumley, R.N., Polmear, I.J., Morton, A.J. (2002). Control of secondary precipitation to improve the performance of aluminum alloys. Forum of Materials Science, 396-402: 893-898. https://doi.org/10.4028/www.scientific.net/MSF.396402.893

[16] Cheng, L.M., Poole, W.J., Embury, J.D., Lloyd, D.J. (2003). The influence of precipitation on the workhardening behavior of the aluminium alloys AA6611 and AA7030. Journal of Metallurgical and Materials Transactions A, 34: 2473-2481. https://doi.org/10.1007/s11661-003-0007-2

[17] Gao, Q.R., Stiller, K., Hansen, V., Oskarsson, A., Danoix, F. (2002). Influence of Aging conditions on the Microstructure and Tensile Strength of aluminium alloy 6063. Forum of Materials Science, 396-402(2): 12111216.

https://doi.org/10.4028/www.scientific.net/MSF.396402.1211

[18] Kilic, S., Kacar, I., Sahinc, M., Ozturkd, F., Erdema, O. (2019). Effects of aging temperature, time, and pre-strain on mechanical properties of AA7075. Materials Research, 22(5): e20190006. http://dx.doi.org/10.1590/1980-5373-MR-2019-0006
[19] Karaaslan, A., Kaya, I., Atapek, H. (2007). Effect of aging temperature and of retrogression treatment time on the microstructure and mechanical properties of AA 7075. Metal Science and Heat Treatment, 49(9): 443-447. https://doi.org/10.1007/s11041-007-0083-9

[20] Kaçara, R., Guleryuzb, K. (2015). Effect of quenching rate and pre-strain on the strain ageing behaviors of 7075 aluminum alloys. Materials Research, 18(2): 328-333. https://doi.org/10.1590/1516-1439.307414

[21] Sato, Y.S., Park, S.H.C., Kokawa, H. (2001). Microstructural factors governing hardness in frictionstir welds of solid-solution-hardened $\mathrm{Al}$ alloys. Metallurgical and Materials Transactions A, 32(12): 3033-3042. https://doi.org/10.1007/s11661-001-0178-7

[22] Mroczka, K., Wojcicka, A., Kurtyka, P. (2012). Aluminium alloy in different heat-treated conditions. Acta Metallurgica Slovaca, 18(2-3): 82-91.

[23] Gowri Shankar, M.C., Shravan, Rakesh, Rahul, Achutha, U., Kini, Sharma, S.S. (2015). Effect of artificial aging on strength and wear behavior of solutionized aluminum 6061 Alloy. International Journal of Industrial and Mechanical Engineering Sciences, 1(1): 10-15.

[24] Howell, Ryan, A. (2009). Microstructural Influence on Dynamic Properties of Age Hardenable FeMnAl Alloys. Missouri University of Science and Technology. 226 pages.

[25] Barsom, J.M. (1975). Development of AASHTO fracture toughness requirements for bridge steels. Engineering Fracture Mechanics, 7(3): 605-608. https://doi.org/10.1016/0013-7944(75)90060-0

[26] Kilic, S., Kacar, I., Sahin, M., Ozturk, F., Erdem, O. (2019). Effects of aging temperature, time, and pre-strain on mechanical properties of AA7075. Materials Research, 22(5): e20190006. http://dx.doi.org/10.1590/1980-5373-mr-2019-0006

[27] Ashjari, M., Feizi, A.J. (2018). 7xxx aluminum alloys; strengthening mechanisms and heat treatment: A review. Material Sci \& Eng Int J., 2(2): 49-53. https://doi.org/10.15406/mseij.2018.02.00034

[28] Liu, Q.J., Xu, X.J., Jiang, C.Y., Zhang, T.C., Mao, Q., Chen, H., Zhang, X. (2019). Effect of solution and aging system on microstructure and mechanical properties of 7000 series aluminum alloy produced by powder metallurgy. Mater. Res. Express in Press, 6(10). https://doi.org/10.1088/2053-1591/ab3a6e

[29] Priya, P., Johnson, D.R., Krane, M.J.M. (2017). Precipitation during cooling of 7XXX aluminum alloys. Computational Materials Science, 139: 273-284. http://dx.doi.org/10.1016/j.commatsci.2017.08.008

[30] He, X., Pan, Q.L., Li, H., Huang, Z.Q., Liu, S.H., Li, K., Li, X.Y. (2019). Effect of artificial aging, delayed aging, and pre-aging on microstructure and properties of 6082 aluminum alloy. Metals, 9(2): 173. https://doi.org/10.3390/met9020173

[31] Holmes, D.R., Rahmel, A. (1977). Materials and Coatings to Resist High Temperature Corrosion. London: Applied Science Publishers, c1978.

[32] Alam, M., Chatterjee, D., Kamat, S., Jayaram, V., Das, D. (2010). Evaluation of ductile brittle transition temperature (DBTT) of aluminide bond coats by microtensile test method. Materials Science and Engineering A Structural Materials: Properties, Microstructures and Processing, 527(26) 7147-7150. https://doi.org/10.1016/j.msea.2010.07.059 
NOMENCLATURE

Oz/gal ounces/gallon

Mpa Mega Pascal

Gpa Giga Pascal

BHN Brinell hardness number

$\mu \mathrm{m} / \mathrm{h} \quad$ micrometer per hour

$\mathrm{mm} \quad$ millimeter

SEM scanning electron microscope

BDTT brittle to ductile transition temperature

hrs hours

${ }^{\circ} \mathrm{C} \quad$ Temperature in degree Celsius
$\mathrm{MPa} \sqrt{\mathrm{m}} \quad$ Unit of fracture toughness measured for area under the notch which is expressed as mega Pascal square root meter

ASTM E American society for testing materials (E 23

23 standards for $\mathrm{V}$ notch impact testing purpose)

$\mathrm{Zn} \quad$ zinc

$\mathrm{Cu} \quad$ copper

$\mathrm{Cr} \quad$ Chromium

$\%$ wt. Percentage weight basis

AL Aluminum material

AA Aluminum alloy

DBTT Ductile to brittle transition temperature 